\title{
Diversity of Lactic Acid Bacteria in the Korean Traditional Fermented Beverage Shindari, Determined Using a Culture-dependent Method
}

\author{
In-Tae Cha ${ }^{1 \dagger}$, Hae-Won Lee ${ }^{1,2 \dagger}$, Hye Seon Song ${ }^{1}$, Kyung June Yim ${ }^{1}$, Kil-Nam Kim ${ }^{1}$, Daekyung Kim ${ }^{1}$, \\ Seong Woon Roh ${ }^{1,3 *}$, and Young-Do Nam ${ }^{3,4 *}$ \\ ${ }^{1}$ Jeju Center, Korea Basic Science Institute, Jeju 690-756, Korea \\ ${ }^{2}$ World Institute of Kimchi, Gwangju 503-360, Korea \\ ${ }^{3}$ University of Science and Technology, Daejeon 305-350, Korea \\ ${ }^{4}$ Fermentation and Functionality Research Group, Korea Food Research Institute, Sungnam 463-746, Korea
}

\begin{abstract}
The fermented food Shindari is a low-alcohol drink that is indigenous to Jeju island, South Korea. In this study, the diversity of lactic acid bacteria (LAB) in Shindari was determined using a culture-dependent method. LAB were cultivated from Shindari samples using two different LAB culture media. Twenty-seven strains were randomly selected and identified by 16S rRNA gene sequence analysis. The identified LAB strains comprised 6 species within the Enterococcus, Lactobacillus and Pediococcus genera. Five of the species, namely Enterococcus faecium, Lactobacillus fermentum, L. plantarum, Pediococcus pentosaceus and P. acidilactici were isolated from MRS medium, while 1 species, L. pentosus, was isolated from Rogosa medium. Most of the isolated strains were identified as members of the genus Lactobacillus (78\%). This study provides basic microbiological information on the diversity of LAB and provides insight into the ecological roles of LAB in Shindari.
\end{abstract}

Keywords: lactic acid bacteria, indigenous fermented food, Shindari, culture-dependent method

The lactic acid bacteria (LAB) are acid-tolerant, low$\mathrm{G}+\mathrm{C}$ content, non-spore-forming, rod- or cocci-shaped Gram-positive microbes that primarily produce lactic acid as the major metabolic end-product of carbohydrate fermentation (Makarova et al., 2006). LAB hold a "generally recognized as safe (GRAS)" status, as they contribute to the normal healthy microflora of human mucosal surfaces and are frequently found in industrially important foods. Historically, LAB have been used for food fermentation, as acidification inhibits the growth of pathogenic microorganisms that can cause damage to human health. Furthermore, the metabolic products of LAB (lactic acid or lactate residue) contribute to the organoleptic and tex-

\footnotetext{
*Corresponding author: Seong-Woon Roh, Jeju Center, Korea Basic Science Institute, Jeju 690-756, Korea.

Tel: 82-64-800-4931, Fax: 82-64-805-7800

E-mail: seong18@gmail.com

Young-Do Nam, Fermentation and Functionality Research Group, Korea Food Research Institute, Sungnam 463-746, Korea.

Tel: 82-31-780-9306, Fax: 82-31-709-9876

E-mail: youngdo98@kfri.re.kr

${ }^{\dagger}$ These authors contributed equally to this work.

Received December 13, 2013; Revised January 2, 2014;

Accepted January 7, 2014
}

tural profile of a food item. Many LAB strains are used for the production of yogurt, cheese, sauerkraut, pickles, beer, wine, cider, and other fermented foods, as well as Korean traditional fermented foods, such as kimchi, doenjang (soybean paste), and jeotgal made of shrimp or shellfish (Cho et al., 2006, Nam et al., 2012a, Nam et al., 2012b, Roh et al., 2010b, Steinkraus, 1983). In many traditional salting processes used for food preservation, vegetables or seafood are submerged in brine, and salt-tolerant $\mathrm{LAB}$ are able to grow by feeding on the natural sugars present in the food. The resulting combination of salt and LAB prevents food spoilage by inhibiting the growth of bacteria and fungi (Caplice and Fitzgerald, 1999). The LAB genera belonged to the order Lactobacillales include Lactobacillus, Leuconostoc, Pediococcus, Lactococcus, and Streptococcus, and the more peripheral Aerococcus, Carnobacterium, Enterococcus, Oenococcus, Sporolactobacillus, Tetragenococcus, Vagococcus, and Weissella.

Shindari, a low-alcohol fermented food indigenous to Jeju island, South Korea, is made via the fermentation of gelatinized rice or barley and the addition of nuruk, which is major ingredient of Korean traditional drinks (Kim et al., 1999). In the past, when cooked rice quickly turned sour as a result of the summer heat, fermentation 
of the rice would generate nutritious alcoholic drinks, such as Shindari. It might be possible to enhance the flavor of Shindari by altering the LAB population used in the fermentation process; however, this has not yet been attempted. The traditional production of Shindari was regionally limited to Jeju island; therefore, it is expected that Shindari possesses a unique LAB population. For this reason, in this study, we sought to discover the diversity of LAB in Shindari samples collected from Jeju island using a culture-dependent method.

Three samples of homemade Shindari were obtained in Jeju island, South Korea. The samples were spread onto MRS (Difco ${ }^{\mathrm{TM}}$ Lactobacilli MRS Agar; BD) and Rogosa (Difco $^{\mathrm{TM}}$ Rogosa SL Agar; BD) plates. The MRS medium contained $\left(\mathrm{g} \cdot \mathrm{L}^{-1}\right)$ : protease peptone no. $3(10.0)$, beef extract (10.0), yeast extract (5.0), dextrose (20.0), polysorbate $80(1.0)$, ammonium citrate (2.0), sodium acetate (5.0), $\mathrm{MgSO}_{4} \cdot 7 \mathrm{H}_{2} \mathrm{O}(0.1), \mathrm{MnSO}_{4} \cdot 4 \mathrm{H}_{2} \mathrm{O}(0.05), \mathrm{K}_{2} \mathrm{HPO}_{4}$ (2.0), and agar (15.0). The Rogosa medium contained $\left(\mathrm{g} \cdot \mathrm{l}^{-1}\right)$ : tryptone (10.0), yeast extract (5.0), dextrose (10.0), arabinose (5.0), saccharose (5.0), sodium acetate (15.0), ammonium citrate (2.0), $\mathrm{KH}_{2} \mathrm{PO}_{4}(6.0), \mathrm{MgSO}_{4} \cdot 7 \mathrm{H}_{2} \mathrm{O}$ $(0.57), \mathrm{MnSO}_{4} \cdot 4 \mathrm{H}_{2} \mathrm{O}(0.12), \mathrm{FeSO}_{4} \cdot 7 \mathrm{H}_{2} \mathrm{O}(0.03)$, polysorbate 80 (1.0), and agar (15.0). The plates were incubated at $25^{\circ} \mathrm{C}$ for $2 \mathrm{wk}$ and the colonies were successively restreaked to obtain pure cultures.

Twenty-seven LAB colonies from the MRS and Rogosa plates were randomly selected and used for further analysis. The 16S rRNA genes of the selected strains were amplified by PCR using the AccuPower PCR PreMix (Bioneer) and the universal 16S ribosomal RNA gene primer set, 27F (5-AGAGTTTGATCMTGGCTCAG-3) and 1492R (5-GGTTACCTTGTTACGACTT-3). The amplified 16S rRNA genes were sequenced using a BigDye Terminator Cycle Sequencing Ready Reaction Kit (Applied Biosystems) together with an automated DNA analyzer system (PRISM 3730XL DNA analyzer, Applied Biosystems), as described previously (Roh et al., 2008). The sequence fragments of the $16 \mathrm{~S}$ rRNA gene were assembled using the SeqMan software program (DNASTAR). Comparisons of the $16 \mathrm{~S}$ rRNA gene sequences were performed using the EzTaxon-e server (http://

Table 1. Bacterial strains identified in this study based on the 16S rRNA gene sequences using the EzTaxon-e database

\begin{tabular}{|c|c|c|c|c|}
\hline No. & Strain & Medium & Taxon* & Identity (\%) \\
\hline 1 & MRS-S1-1 & MRS & Lactobacillus fermentum CECT $562^{\mathrm{T}}$ & 100.0 \\
\hline 2 & MRS-S1-2 & MRS & Enterococcus faecium ATCC $19434^{\mathrm{T}}$ & 99.9 \\
\hline 3 & MRS-S1-3 & MRS & Lactobacillus plantarum subsp. plantarum ATCC $14917^{\mathrm{T}}$ & 99.5 \\
\hline 4 & MRS-S1-4 & MRS & Lactobacillus plantarum subsp. plantarum ATCC $14917^{\mathrm{T}}$ & 99.9 \\
\hline 5 & MRS-S1-5 & MRS & Lactobacillus plantarum subsp. plantarum ATCC $14917^{\mathrm{T}}$ & 99.9 \\
\hline 6 & MRS-S1-6 & MRS & Lactobacillus fermentum CECT $562^{\mathrm{T}}$ & 99.9 \\
\hline 7 & MRS-S1-7 & MRS & Lactobacillus plantarum subsp. plantarum ATCC $14917^{\mathrm{T}}$ & 100.0 \\
\hline 8 & MRS-S1-8 & MRS & Lactobacillus fermentum CECT $562^{\mathrm{T}}$ & 99.9 \\
\hline 9 & MRS-S1-9 & MRS & Lactobacillus fermentum CECT $562^{\mathrm{T}}$ & 99.9 \\
\hline 10 & MRS-S1-10 & MRS & Lactobacillus fermentum CECT $562^{\mathrm{T}}$ & 100.0 \\
\hline 11 & MRS-S2-3 & MRS & Lactobacillus fermentum CECT $562^{\mathrm{T}}$ & 99.8 \\
\hline 12 & MRS-S2-4 & MRS & Lactobacillus fermentum CECT $562^{\mathrm{T}}$ & 99.9 \\
\hline 13 & MRS-S2-8 & MRS & Lactobacillus fermentum CECT $562^{\mathrm{T}}$ & 99.9 \\
\hline 14 & MRS-S3-1 & MRS & Pediococcus pentosaceus DSM $20336^{\mathrm{T}}$ & 99.9 \\
\hline 15 & MRS-S3-3 & MRS & Lactobacillus fermentum CECT $562^{\mathrm{T}}$ & 99.9 \\
\hline 16 & MRS-S3-5 & MRS & Lactobacillus fermentum CECT $562^{\mathrm{T}}$ & 99.9 \\
\hline 17 & MRS-S3-6 & MRS & Pediococcus acidilactici DSM $20284^{\mathrm{T}}$ & 99.8 \\
\hline 18 & MRS-S3-7 & MRS & Pediococcus acidilactici DSM $20284^{\mathrm{T}}$ & 99.2 \\
\hline 19 & MRS-S3-9 & MRS & Lactobacillus fermentum CECT $562^{\mathrm{T}}$ & 99.9 \\
\hline 20 & MRS-S3-10 & MRS & Lactobacillus fermentum CECT $562^{\mathrm{T}}$ & 99.9 \\
\hline 21 & MRS-S3-11 & MRS & Lactobacillus plantarum subsp. plantarum ATCC $14917^{\mathrm{T}}$ & 99.9 \\
\hline 22 & MRS-S3-12 & MRS & Pediococcus pentosaceus DSM $20336^{\mathrm{T}}$ & 99.9 \\
\hline 23 & MRS-S3-13 & MRS & Pediococcus pentosaceus DSM $20336^{\mathrm{T}}$ & 99.9 \\
\hline 24 & Rogosa-S1-5 & Rogosa & Lactobacillus pentosus JCM $1558^{\mathrm{T}}$ & 100.0 \\
\hline 25 & Rogosa-S1-6 & Rogosa & Lactobacillus pentosus JCM $1558^{\mathrm{T}}$ & 100.0 \\
\hline 26 & Rogosa-S1-9 & Rogosa & Lactobacillus pentosus JCM $1558^{\mathrm{T}}$ & 100.0 \\
\hline 27 & Rogosa-S2-5 & Rogosa & Lactobacillus pentosus JCM $1558^{\mathrm{T}}$ & 100.0 \\
\hline
\end{tabular}

*CECT, Spanish Type Culture Collection; ATCC, American Type Culture Collection; DSM, Deutsche Sammlung von Mikroorganismen und Zellkulturen GmbH; JCM, Japan Collection of Microorganisms; ${ }^{\mathrm{T}}$, type strain 


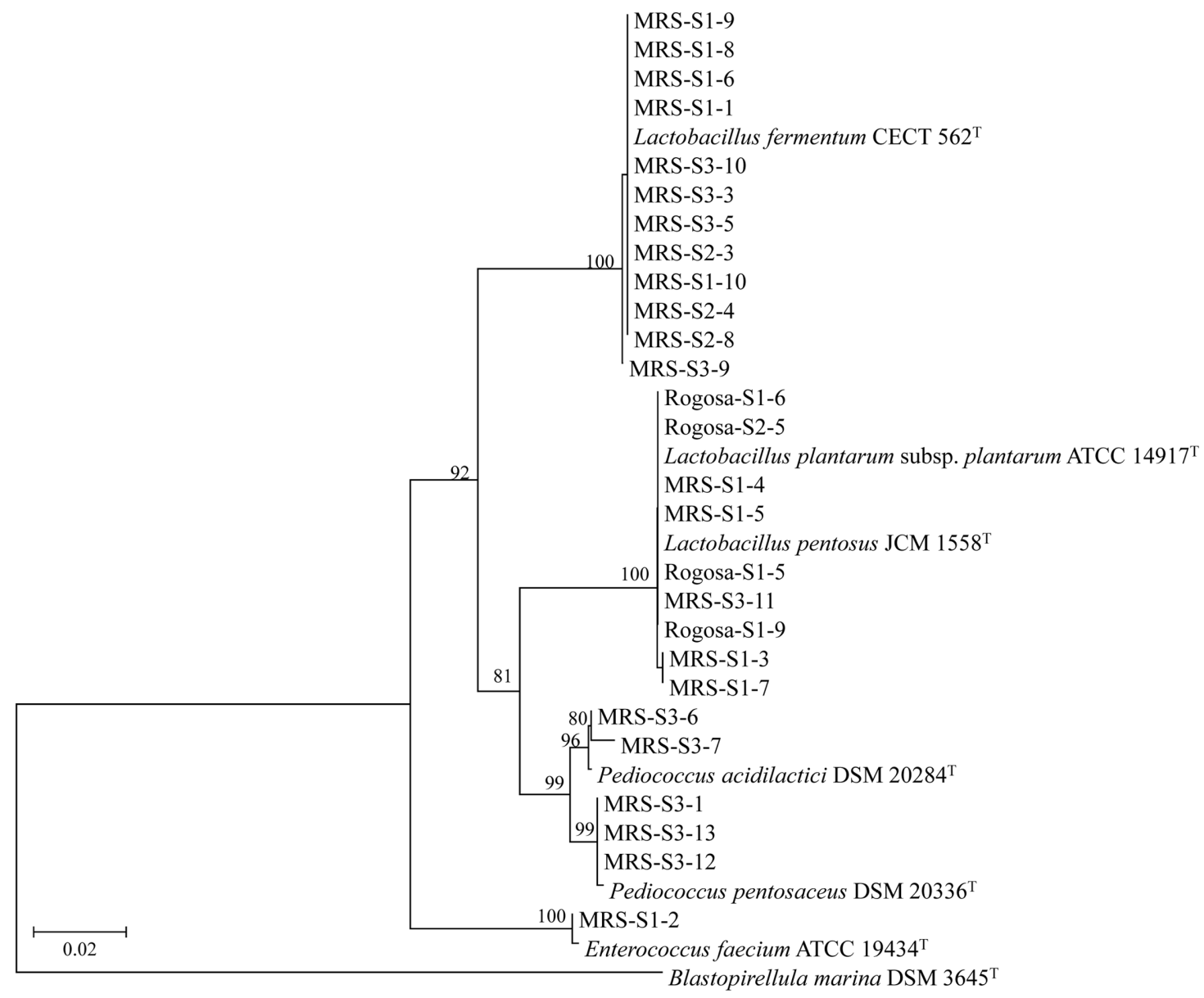

Fig. 1. Neighbor-joining (NJ) phylogenetic tree of the isolates from Shindari samples and phylogenetically closed relatives, based on $16 \mathrm{~S}$ rRNA gene sequences. The bootstrap values $(>70 \%)$ calculated using the $\mathrm{NJ}$ probabilities are shown at the branching points. Balstopirellula marina DSM $3645^{\mathrm{T}}$ served as the outgroup. Bar, 0.02 accumulated changes per nucleotide.

eztaxon-e.ezbiocloud.net/) (Kim et al., 2012) to identify the nearest related taxa and calculate the pairwise $16 \mathrm{~S}$ rRNA gene sequence similarities. The 16S rRNA gene sequences of LAB strains and related taxa were aligned using the SILVA Incremental Aligner (Pruesse et al., 2012). A phylogenetic tree was constructed based on the aligned 16S rRNA gene sequences using MEGA5 (Tamura et al., 2011) and the neighbor-joining method (Saitou and Nei, 1987). A bootstrap analysis was performed by obtaining a consensus tree based on 1000 randomly generated trees.

The 16S rRNA gene sequence analysis revealed that the 27 strains comprised 5 species and 1 subspecies within 3 genera, namely Lactobacillus, Pediococcus, and Enterococcus. All of these genera belong to the class Baclli within the phylum Firmicutes. The genera Lactobacillus, Pediococcus, and Enterococcus are members of the order Lactobacillales. Twenty-one of the 27 strains analyzed belong to the genus Lactobacillus (78\%), while the rest belong to the genera Pediococcus (5 strains) and Enterococcus (1 strain). The identified Lactobacillus spp. were found to be highly similar to L. fermentum (99.8 100.0\% 16S rRNA gene sequence similarity), L. plantarum subsp. plantarum $(99.5 \sim 100.0 \%$ similarity) and L. pentosus (100.0\% similarity). Other LAB strains were closely related to P. pentosaceus (99.9\% similarity), P. acidilactici (99.2 99.8\% similarity) and E. faecium (99.9\% similarity) (Table 1).

Many bacterial strains were originally isolated from fermented food. Members of the genus Lactobacillus are particularly well-known LAB, and are present in the normal flora of the vagina and gastrointestinal tract of human. The production of lactic acid makes these environments acidic, which inhibits the growth of some harmful bacteria (Osset et al., 2001; Reid et al., 2009). Interestingly, L. plantarum is commonly found in many fermented food products including sauerkraut, pickles, brined olives, kimchi, Nigerian Ogi, sourdough, and other 
fermented plant material, and also some cheeses, fermented sausages, and stockfish (Jang and Kim, 2013). L. fermentum is also a normal inhabitant of the human intestinal tract, and some strains have been associated with cholesterol metabolism (Mikelsaar and Zilmer, 2009; Pan et al., 2011).

In this study, 27 LAB strains isolated from Shindari samples were analyzed using MRS and Rogosa LABselection media. However, culture-dependent methods cannot be used to analyze the whole bacterial population of a given sample. These classical methods must be used in complement with culture-independent methods, such as metagenome or amplicon sequencing using next-generation sequencing technologies (Roh et al., 2010a). The full extent of the population of LAB and other types of bacteria present in Shindari remains to be determined. This study provides basic microbiological information on the diversity of $\mathrm{LAB}$ and provides insight into the ecological roles of LAB in Shindari.

\section{Acknowledgments}

This work was supported by the Basic Science Research Program through the National Research Foundation of Korea (NRF) (2012R1A1A2040922).

\section{References}

Caplice E and Fitzgerald GF (1999) Food fermentations: Role of microorganisms in food production and preservation. Int. $J$. Food Microbiol. 50, 131-149.

Cho J, Lee D, Yang C, Jeon J, Kim J, and Han H (2006) Microbial population dynamics of kimchi, a fermented cabbage product. FEMS Microbiol. Lett. 257, 262-267.

Jang JY and Kim TW (2013) Lactic acid bacteria in Kimchi and their immunomodulatory activities. Curr. Top. LAB Probiotics 1, 28-37.

Kim OS, Cho YJ, Lee K, Yoon SH, Kim M, Na H, Park SC, Jeon YS, Lee JH, Yi H, Won S, and Chun J (2012) Introducing EzTaxon-e: a prokaryotic 16S rRNA gene sequence database with phylotypes that represent uncultured species. Int. J. Syst. Evol. Microbiol. 62, 716-721.

Kim SC, Kim HS, and Kang YJ (1999) Changes of components in the rice-porridge fermented by nuruk. Korean Soc. Food Sci. Nutr. 28, 1017-1021.

Makarova K, Slesarev A, Wolf Y, Sorokin A, Mirkin B, Koonin E, Pavlov A, Pavlova N, Karamychev V, Polouchine N, Shakhova V, Grigoriev I, Lou Y, Rohksar D, Lucas S, Huang K, Goodstein DM, Hawkins T, Plengvidhya V, Welker D,
Hughes J, Goh Y, Benson A, Baldwin K, Lee JH, DiazMuniz I, Dosti B, Smeianov V, Wechter W, Barabote R, Lorca G, Altermann E, Barrangou R, Ganesan B, Xie Y, Rawsthorne H, Tamir D, Parker C, Breidt F, Broadbent J, Hutkins R, O'Sullivan D, Steele J, Unlu G, Saier M, Klaenhammer T, Richardson P, Kozyavkin S, Weimer B, and Mills D (2006) Comparative genomics of the lactic acid bacteria. Proc. Natl. Acad. Sci. U. S. A. 103, 15611-15616.

Mikelsaar M and Zilmer M (2009) Lactobacillus fermentum ME3 - an antimicrobial and antioxidative probiotic. Microb. Ecol. Health Dis. 21, 1-27.

Nam YD, Lee SY, and Lim SI (2012a) Microbial community analysis of Korean soybean pastes by next-generation sequencing. Int. J. Food Microbiol. 155, 36-42.

Nam YD, Park SL, and Lim SI (2012b) Microbial composition of the Korean traditional food "kochujang" analyzed by a massive sequencing technique. J. Food Sci. 77, M250-256.

Osset J, Bartolome RM, Garcia E, and Andreu A (2001) Assessment of the capacity of Lactobacillus to inhibit the growth of uropathogens and block their adhesion to vaginal epithelial cells. J. Infect. Dis. 183, 485-491.

Pan DD, Zeng XQ, and Yan YT (2011) Characterisation of Lactobacillus fermentum SM-7 isolated from koumiss, a potential probiotic bacterium with cholesterol-lowering effects. $J$. Sci. Food Agric. 91, 512-518.

Pruesse E, Peplies J, and Glockner FO (2012) SINA: accurate high-throughput multiple sequence alignment of ribosomal RNA genes. Bioinformatics 28, 1823-1829.

Reid G, Dols J, and Miller W (2009) Targeting the vaginal microbiota with probiotics as a means to counteract infections. Curr. Opin. Clin. Nutr. Metab. Care. 12, 583-587.

Roh SW, Abell GC, Kim KH, Nam YD, and Bae JW (2010a) Comparing microarrays and next-generation sequencing technologies for microbial ecology research. Trends Biotechnol. 28, 291-299.

Roh SW, Kim KH, Nam YD, Chang HW, Park EJ, and Bae JW (2010b) Investigation of archaeal and bacterial diversity in fermented seafood using barcoded pyrosequencing. ISME J. 4, 1-16.

Roh SW, Sung Y, Nam YD, Chang HW, Kim KH, Yoon JH, Jeon CO, Oh HM, and Bae JW (2008) Arthrobacter soli sp. nov., a novel bacterium isolated from wastewater reservoir sediment. J. Microbiol. 46, 40-44.

Saitou N and Nei M (1987) The neighbor-joining method: a new method for reconstructing phylogenetic trees. Mol. Biol. Evol. 4, 406-425.

Steinkraus KH (1983) Lactic acid fermentation in the production of foods from vegetables, cereals and legumes. Antonie Van Leeuwenhoek 49, 337-348.

Tamura K, Peterson D, Peterson N, Stecher G, Nei M, and Kumar S (2011) MEGA5: molecular evolutionary genetics analysis using maximum likelihood, evolutionary distance, and maximum parsimony methods. Mol. Biol. Evol. 28, 2731-2739. 